\title{
PTEN Mutation Analysis Testing Method
}

National Cancer Institute

\section{Source}

National Cancer Institute. PTEN Mutation Analysis Testing Method. NCI Thesaurus. Code C158947.

A request to enter the specific molecular analysis method used to detect and identify mutations in the PTEN gene. 